\title{
Determinants of Low Birth Weight Among Newborns Delivered in Public Hospitals in Addis Ababa, Ethiopia: Case-Control Study
}

This article was published in the following Dove Press journal: Pediatric Health, Medicine and Therapeutics

\author{
Getaneh Baye Mulu (D) \\ Bereket Gebremichael $^{2}$ \\ Kalkidan Wondwossen Desta ${ }^{2}$ \\ Mekonen Adimasu Kebede (iD ${ }^{2}$ \\ Yared Asmare Aynalem (D) \\ Melaku Bimirew Getahun ${ }^{3}$ \\ 'College of Health Sciences, Debre \\ Berhan University, Debre Berhan, \\ Ethiopia; ${ }^{2}$ College of Health Science, \\ Addis Ababa University, Addis Ababa, \\ Ethiopia; ${ }^{3}$ College of Health Sciences, \\ Woldia University, Woldia, Ethiopia
}

Correspondence: Getaneh Baye Mulu Email getanehbaye6@gmail.com
Background: Birth weight predicts the infant's future health, growth, and viability. It is a good summary measure of many public health problems that include long-term maternal malnutrition, and poor health care during pregnancy. In developing countries, a birth weight below $2500 \mathrm{~g}$ is the leading cause of infant and child mortality. In Ethiopia, LBW had more than $13 \%$ prevalence. Determinants of low birth weight were yet to be completely understood. Therefore, this study investigates the predictors of low birth weight.

Objective: To identify determinants of low birth weight among newborns delivered at Addis Ababa public hospitals, 2019.

Methods: Institution-based unmatched case-control study was conducted among 279 (93 cases and 186 controls) newborns delivered from March 15 to April 30, 2019, in Addis Ababa public hospitals. Consecutive and systematic random sampling were employed to select cases and controls, respectively. Data were collected by interview using structured and pretested questionnaire. Finally, data were entered using Epi-data 4.2 and analysed using SPSS version 25. Factors having P-value $<0.25$ in the bivariable logistic regression model were entered into a multivariable logistic regression model. Statistical significance was declared at P-value $\leq 0.05$.

Results: From 279 selected participants, 270 new-borns (90 cases and 180 controls) participated. In logistic regression model, significant association was found with gestational hypertension [AOR 3.7 (95\% CI 1.6-8.7)], maternal height [AOR 5.7 (95\% CI 1.7-19.7)], incomplete antenatal visit [AOR 6.7 (95\% CI 3.2-15.3)], and low maternal educational status [AOR 3.8 (95\% CI 1.3-10.9)].

Conclusion: Predictors of low birth weight were maternal height $<155 \mathrm{~cm}$, complications during pregnancy, gestational hypertension, and incomplete Antenatal visit, and low maternal education. Stakeholders would better work together to reduce low birth weight by preparing appropriate intervention and monitoring policy.

Keywords: low birth weight, determinants, case-control, Addis Ababa

\section{Introduction}

World Health Organization (WHO) defines Low Birth Weight (LBW) as the weight of a neonate below $2500 \mathrm{~g}$ at birth, often corresponding to the 10th percentile for its gestational age. ${ }^{1}$ Birth weight is a key indicator of the child's vulnerability to the risk of childhood diseases. It also predicts the child's future health, growth, and development, and the probability of survival. LBW frequently resulted from preterm birth, intrauterine growth restriction, or a combination of both pathophysiologic conditions. ${ }^{2}$ Newborns weighing less than $2500 \mathrm{~g}$ are approximately 20 times more likely to die than normal birth weight babies. ${ }^{3}$ 
Worldwide neonates born LBW are around 20 million, of which $95 \%$ live in developing countries. Moreover, Africa with $18.3 \%$ of high burden of LBW is only preceded by Asia, which accounts for $14.3 \%{ }^{4}$ Low birth weight is considered the single most important risk factor of infant mortality, mainly in deaths that occur within the first 28 days of life. ${ }^{5}$ Moreover, three fourth of neonatal deaths globally occurred among low birth weight. ${ }^{1}$

Thus, low birth weight is an indicator of the status of public health, maternal health, and nutrition. It continues to be associated with a range of both short- and long-term consequences unless early screening and treatment are given. Long-term complications associated with LBW include hypertension, diabetes mellitus, proteinuria, and renal disease in late age, eye problems like strabismus and myopia, deafness, neurologic complications like cerebral palsy, developmental delay with low Intelligence Quotient (IQ), seizure and psychological disturbance., ${ }^{6,7}$

In developing countries, the main cause of infant and child mortality is LBW. ${ }^{3}$ Low birth weight newborns who survive will have poor immune function and increased risk of disease; they are prone to malnutrition, with reduced muscle strength throughout the lifespan, and suffer by higher incidence of cardiovascular disease, cognitive disabilities, and a lower IQ, which affects their school performance and job opportunities later. ${ }^{3,8}$ In the last 10 years, the incidence of LBW has not declined in SubSaharan Africa (SSA) and Asia. ${ }^{9}$

In Africa, low birth weight is approximately $22 \%$, and in sub-Saharan Africa, it is around $13-15 \%$ with a small variation across the continent. ${ }^{10}$ According to the assessment carried out by the United Nations Children's Fund (UNICEF), the national prevalence of LBW in Ethiopia was $20 \%{ }^{11}$

Having basic knowledge about predictors for low birth weight is important to identify and to give appropriate attention to those mothers at risk. The Ethiopian government appreciates the severity of low birth weight, and some measures are addressed by the Ministry of Health, non-governmental organizations, WHO and health professionals like Ethiopian pediatric associations. ${ }^{12,13}$

The etiology of LBW is yet to be completely understood even though several studies have attempted to unravel the underlying causes. Constitutional factors, such as sex, maternal height, and weight have been identified as risk factors for LBW. ${ }^{1-3}$ On the other hand, in different studies, factors like lack of antenatal follow-up, preterm delivery, chronic medical illness, lack of formal education and young age of the mother have been reported to be associated with low birth weight. ${ }^{4-6}$

Despite the high prevalence of LBW, only a few kinds of literature are available to show determinants of low birth weight. Therefore, findings of this study will add to the current knowledge about predictors of low birth weight particularly regarding nutritional factors, maternal Mid Upper Arm Circumference (MUAC), Body Mass Index (BMI) which has not been well explained by other studies. This will have great relevance for nursing education, practice, and research for designing appropriate measures and undertaking timely interventions.

\section{Methods and Materials}

\section{Study Design, Area, Period, and Population and Eligibility Criteria}

An institution-based unmatched case-control study was conducted in four randomly selected public hospitals of Addis Ababa, Ethiopia from March 15 to April 30, 2019.

Source population: all newborns delivered in Addis Ababa public hospitals were the source population. Whereas all newborns delivered in selected public hospitals of Addis Ababa were the study population.

Case: Those live singleton term babies with birth weight less than $2500 \mathrm{~g}$.

Control: Those term newborns whose birth weight ranges from 2500 to less than $4000 \mathrm{~g}$.

Eligibility criteria: all newborns with low birth weight and normal birth weight were included. Newborns with multiple births, visible deformity, and preterm were excluded from the study because those conditions are known as risk factors for low birth weight.

\section{Sample Size Determination and Sampling Approach}

The sample size was determined by using Open Epi version 7.2.0.1 using double population proportion exposure difference formula by considering major determinant variables (mothers with no formal education, mothers with no history of nutrition counselling during pregnancy, mothers from food-insecure households and those mothers who had no ANC visit). ${ }^{14}$ Considering mothers with no formal education (proportion $=42 \%$ with OR 2.2$)^{14}$ as independent predictor since it gives maximum sample size as compared to other exposure variables. Following the assumptions (95\% CI, 80\% power and 1:2 control to case ratio the 
sample size was 254). By adding $10 \%$ non-response rate the final sample size was 279 (93 cases and 186 controls).

\section{Sampling Technique and Procedure}

Four public hospitals: (Petros, Yekatit 12, Gandhi memorial and Tirunesh Beijing hospitals) were selected by lottery method from twelve public hospitals in Addis Ababa. Proportional allocation was made for each hospital by fixing 1-month average delivery flow. From 1600 deliveries 122 were cases and 1478 were controls. Then, cases were selected by consecutive sampling. Controls were sampled systematically every eighth interval $(1478 / 186=8)$ from the delivery of the same hospitals from which cases were drawn. The weight of all live term singleton newborns during the study period was measured. Based on the case definition, those live term newborns birth weight less than $2500 \mathrm{~g}$ were included in the study as cases.

\section{Variables of the Study}

Dependent variables: birth weight (LBW or normal birth weight)

\section{Independent Variables}

Socio-demographic variables: (Infant's sex, marital status, maternal age, the weight of the mother, maternal education, maternal BMI, religion, ethnicity, maternal stature, maternal occupation, monthly income of the family, smoking status).

Obstetric factors: (gestational age, parity, Antenatal Care (ANC) visit, anemia, history of abortion, hypertension (HTN), gravidity, Antepartum hemorrhage (APH)).

Nutritional factors: maternal MUAC, nutrition counselling during pregnancy, frequency of additional meal intake, prenatal iron supplementation.

\section{Data Collection Tools and Procedures}

The data were collected by interviewing the mothers, observing medical records and measuring the anthropometry of the mothers and the newborns using structured and pretested questionnaires. The interview and anthropometric measurements were conducted by 8 trained midwives working in delivery rooms of the four public hospitals and 4 supervisors. The questionnaire was adopted from Ethiopian demographic health survey. ${ }^{15}$

The socio-demographic, obstetric, and nutritional factors of the questionnaire were obtained from the maternal interviews, and document review. Newborn's birth weight was measured within 1-2 hrs after birth by using balanced seca scale. The scale measures starting from 50 grams (g) (lowest) to 20 kilograms (highest) and rounded to the nearest $50 \mathrm{~g}$. The scale interval was $50 \mathrm{~g}$. Mothers who fulfill the inclusion criteria were interviewed face to face within a day after delivery. The height of the mother was measured against a wall height scale to the nearest centimetre. MUAC of mothers was measured by MUAC tape and rounded to the nearest $0.1 \mathrm{~cm}$.

\section{Data Quality Control Measures}

The questionnaire was first prepared in English and translated to Amharic language and back to English to check for language consistency by an independent translator. The data collection instrument was pre-tested on $5 \%$ of the sample size in Black Lion referral hospital before actual data collection was made. The pre-test was used to check for language clarity, appropriateness of data collection tools, time estimation and for the necessary adjustment. The weighing balanced scale was checked and adjusted to zero before weighing the next newborn.

Training concerning the data collection tool and data collection process has been given for both data collectors and supervisors. During the data collection, supervision was conducted by supervisors and principal investigators for the quality of data. Finally, all the collected data were also checked by the supervisor and investigator for its completeness and accuracy. Consistency has been examined through a random selection of questionnaires.

\section{Data Processing and Analysis}

Before analysis, data were cleaned and coded. Identified errors during this time were adjusted after a review of the original data using the code numbers. Data were entered using Epi-Data version 4.2.1 and analysed using SPSS 25 statistical software. Socio-demographic profiles of variables frequency distribution, summary measures such as mean and standard deviation were calculated for cases and controls. When frequencies become smaller than expected, variables were re-categorized or merge of the levels was done. Determinants associated with LBW were identified using bivariable and multivariable logistic regression models. Independent determinants that showed near to statistically significant association ( $p$-value less than 0.25 ) and predictors with large effect size in literature with the dependent variable in the bivariable models were considered candidate variables for the multivariable logistic regression models. To minimize adjustment bias, direct and indirect factors of LBW were fitted separately into two multivariable models. The indirect 
factors include socio-demographic and economic features and maternal age, whereas direct factors comprise maternal height, pre-pregnancy weight, gestational weight gain, parity, infant's sex, alcohol drinking, and cigarette smoking. In the final multivariable models, the level of multicollinearity was checked and fitted using variance inflation factor (VIF) and tolerance and found within a tolerable range (all variables of variance inflation factor value were $>1$ and $<5$ ) and tolerance (all variables value $>0.2$ ). In the final multivariable models, goodness of fit, Hosmer Lemeshow was checked and fitted for the data with the P-value 0.124. In a multivariable regression, P-value, less than 0.05 , was considered statistically significant. Finally, results were presented in the form of tables and graphs.

\section{Results}

\section{Socio-Demographic Factors of the Mother and Newborn}

In this study, from a total of 279 sampled populations, 270 new-borns (90 cases and 180 controls) were included which made the response rate $96.8 \%$ for both cases and controls. Nearly half the cases $(53.3 \%)$ and controls $(52.2 \%)$ were males. The mean birth weight of the neonates was $2849 \pm 540 \mathrm{~g}$ (gram) with the minimum and maximum birth weight of new-borns $1800 \mathrm{~g}$ and $4000 \mathrm{~g}$, respectively. The gestational age of the new-born was ranged from 37 to 43 weeks with a mean of 38.8 weeks.

The mean height and BMI of the respondent were $160.7 \mathrm{~cm}$ and $21.8 \mathrm{~kg} / \mathrm{m}^{2}$ respectively. Sixty percent of cases and $70 \%$ controls BMI fall to normal range $\left(18.5-24.9 \mathrm{~kg} / \mathrm{m}^{2}\right)$. The mean monthly income of the family was 3920 Ethiopian birr (Table 1).

\section{Obstetric Factors}

Nearly half of the case mothers $47(52.2 \%)$ were primigravida and $43(47.8 \%)$ were multigravida. From the control group, 65(36.1\%) of the mothers were primigravida, and two-third 115 (63.9\%) were multigravida. Mothers who had a history of abortion in both cases and control groups were $23.3 \%$ and $23.3 \%$, respectively. Nearly one-third 34 (37.8\%) case and 26 (14.4\%) control group mothers had experienced pregnancy-related complications. Regarding pregnancy-related complications, 14(15.6\%), 28(31.1\%) and $4(4.4 \%)$ had Anemia, gestational HTN and Chronic HTN in the case group, respectively. From the control group mothers, $17(9.4 \%), 28(15.6 \%)$ and $6(3.3 \%)$ of them had Anaemia, gestational HTN and Chronic HTN,
Table I Frequency Distribution of Socio-Demographic Characteristics Among Case and Control Groups in Public Hospitals Addis Ababa, 2019

\begin{tabular}{|c|c|c|c|c|}
\hline \multirow[t]{2}{*}{ Variable } & \multicolumn{2}{|c|}{ Case $(\mathrm{N}=90)$} & \multicolumn{2}{|c|}{ Control $(\mathrm{N}=180)$} \\
\hline & $\mathbf{N}$ & $\%$ & $\mathbf{N}$ & $\%$ \\
\hline \multicolumn{5}{|l|}{ Infant sex } \\
\hline Male & 48 & 53.3 & 94 & 52.2 \\
\hline Female & 42 & 46.7 & 86 & 47.8 \\
\hline \multicolumn{5}{|l|}{ Maternal age } \\
\hline$<20$ & 20 & 22.2 & 13 & 7.2 \\
\hline $20-34$ & 61 & 67.8 & 157 & 87.2 \\
\hline$\geq 35$ & 9 & 10 & 10 & 5.6 \\
\hline \multicolumn{5}{|l|}{ Religion } \\
\hline Muslim & 12 & 13.3 & 46 & 25.6 \\
\hline Orthodox & 69 & 76.7 & 121 & 67.2 \\
\hline Protestant & 9 & 10 & 13 & 7.2 \\
\hline \multicolumn{5}{|l|}{ Marital status } \\
\hline Married & 78 & 86.7 & 159 & 88.3 \\
\hline Divorced & 5 & 5.5 & 10 & 5.6 \\
\hline Single & 7 & 7.8 & 11 & 6.1 \\
\hline \multicolumn{5}{|l|}{ Education } \\
\hline Illiterate & 13 & 14.4 & 16 & 8.9 \\
\hline Primary & 33 & 36.7 & 68 & 37.8 \\
\hline Secondary & 33 & 36.7 & 49 & 27.2 \\
\hline Higher & 11 & 12.2 & 47 & 26.1 \\
\hline \multicolumn{5}{|l|}{ Occupation } \\
\hline Housewife & 40 & 44.4 & 74 & 41.1 \\
\hline Merchant & 12 & 13.3 & 20 & II.I \\
\hline gov.t employee & 15 & 16.7 & 28 & 15.6 \\
\hline Private & 23 & 25.6 & 58 & 32.2 \\
\hline \multicolumn{5}{|l|}{ Household monthly income } \\
\hline$<1650$ ETB & II & 12.2 & 19 & 10.6 \\
\hline 1650-3299 ЕTВ & 39 & 43.3 & 53 & 29.4 \\
\hline 3200-5249 ЕТВ & 25 & 27.8 & 70 & 38.9 \\
\hline$\geq 5250$ ETB & 15 & 16.7 & 38 & 21.1 \\
\hline
\end{tabular}

Abbreviations: gov.t, government; ETB, Ethiopian birr.

respectively. Most of the case group mothers 52(57.8\%) delivered vaginally. The rest $4(4.4 \%)$ and $34(37.8 \%)$ delivered by instrumental and CS, respectively.

\section{Nutritional Factors}

About half of the case group mothers had nutritional counselling during pregnancy, whereas from the control group mothers, $123(68.3 \%)$ of them had nutritional counselling during pregnancy. Thirty-five (38.9\%) case group and $43(23.9 \%)$ control group mothers had MUAC less than $23 \mathrm{~cm}$. Above two-third of case group mothers 65 
Table 2 Frequency Distribution of Nutritional Factors Among Case and Control Groups in Public Hospitals Addis Ababa, 2019

\begin{tabular}{|l|l|l|l|l|}
\hline \multirow{2}{*}{ Variable } & \multicolumn{2}{|l|}{$\begin{array}{l}\text { Case } \\
(\mathbf{N}=90)\end{array}$} & \multicolumn{2}{l|}{$\begin{array}{l}\text { Control } \\
(\mathbf{N}=180)\end{array}$} \\
\cline { 2 - 5 } & $\mathbf{N}$ & $\%$ & $\mathbf{N}$ & $\%$ \\
\hline $\begin{array}{l}\text { Nutritional counselling during pregnancy } \\
\text { Yes }\end{array}$ & 44 & 48.9 & 123 & 68.3 \\
No & 46 & 51.1 & 57 & 31.7 \\
\hline $\begin{array}{l}\text { Additional meals during pregnancy } \\
\text { Yes }\end{array}$ & 32 & 35.6 & 103 & 57.2 \\
No & 58 & 64.4 & 77 & 42.8 \\
\hline $\begin{array}{l}\text { Iron during Pregnancy } \\
\text { Yes }\end{array}$ & 65 & 72.2 & 145 & 80.6 \\
No & 25 & 27.8 & 35 & 19.4 \\
\hline Maternal MUAC & & & & \\
$<23 \mathrm{~cm}$ & 35 & 38.9 & 43 & 23.9 \\
$\geq 23 \mathrm{~cm}$ & 55 & 61.1 & 137 & 76.1 \\
\hline Alcohol drunk during pregnancy & & & & \\
Yes & 9 & 10 & 17 & 9.4 \\
No & 81 & 90 & 163 & 90.6 \\
\hline
\end{tabular}

Abbreviations: MUAC, Mid-upper arm circumference; $\mathrm{Cm}$, centimetre.

(72.2\%) had iron supplement during pregnancy, whereas in the control group mothers, $145(80.6 \%)$ of them had iron supplement during pregnancy (Table 2).

\section{Determinants of Low Birth Weight}

Those determinants like maternal education, parity, pregnancy complication, gestational hypertension, nutritional counselling, maternal height, age of the mother, iron supplementation, anaemia, additional meals intake, maternal BMI, incomplete ANC visit, maternal MUAC, pre-pregnancy weight, gravidity had P-value less than 0.25 in bivariable logistic regression. Those variables were entered into multivariable logistic regression for further analysis.

Variables having a statistically significant association in multivariable logistic regression were mothers in secondary education level, pregnancy-related complication, gestational hypertension, mothers with low maternal stature $<155 \mathrm{~cm}$, and incomplete antenatal visit.

The odds of giving LBW were three times in mothers with pregnancy-related complication than mothers without pregnancy-related complications [AOR 3.08 (95\% CI 1.4-6.8), $\mathrm{P}=0.05]$. Similarly, the odds of LBW were four times more likely among mothers who had gestational HTN than mothers without gestational hypertension with [AOR 3.7 (95\% CI $1.6-8.7), P=0.02]$. Likewise, mothers with low maternal stature $\leq 155 \mathrm{~cm}$ were six times more likely to deliver LBW than mothers having stature $>155 \mathrm{~cm}$ [AOR $5.7(95 \% \mathrm{CI}$ $1.7-19.7), P=0.006]$. Furthermore, mothers who had incomplete Antenatal visits (1-3 visits) were seven times more likely to give LBW than mothers four or more antenatal visits with [AOR 6.7 (95\% CI 3.2-15.3), $\mathrm{P}=0.00$ ]. Mothers in secondary education level were four times more likely to give LBW than mothers in higher education level [AOR 3.76 (95\% CI 1.294-10.9), $\mathrm{P}=0.015$ ] (Table 3).

\section{Discussion}

Low birth weight remains a significant cause of morbidity and mortality among neonates and children. This study was conducted on the determinants of LBW among newborns delivered at Addis Ababa Public Hospitals.

In this study low maternal stature was a significant determinant of low birth weight. Mothers who have height of $<155 \mathrm{~cm}$ were six times the odds of giving low birth weight than those with $>155 \mathrm{~cm}$ height [AOR (95\% CI 5.7 (1.65-19.7))]. This finding is comparable with the finding done in Cameroon, ${ }^{16}$ Morocco, ${ }^{17}$ India and Eastern Nepal ${ }^{18,19}$ where maternal stature was a significant predictor of LBW. This may be due to the fact that mothers who are short stature may also have a narrow pelvis, end up with limited intrauterine space that restricts intrauterine fetal growth finalized with low birth weight. ${ }^{20}$

According to this study, mothers who had three or fewer ANC visits were 6.9 times more likely to give birth to LBW than those who had four and above visits with [AOR 6.99 (95\% CI 3.2-15.29)]. Similar findings were found in a study conducted in Amhara region, ${ }^{21}$ Morocco, ${ }^{17}$ India and Eastern Nepal. ${ }^{18,19}$ This is related with ANC visits of the pregnant mother are very important to minimize adverse pregnancy outcomes including LBW as they provide chances for evaluating the foetal wellbeing and permit management soon by improving the health and wellbeing of the mother and preventing further complications by early detection and treatment of diseases. ${ }^{22}$

Gestational hypertension was another predictor of LBW. According to this study, mothers who had gestational hypertension had four times increased odds of giving birth to low birth weight babies than their counterparts [AOR 3.73 (95\% CI, 1.6-8.65)]. This result is consistent with a case-control study done in Debre Markos ${ }^{23}$ and a cross-sectional study in Gondar town. ${ }^{5}$ This result was also supported by similar studies done in Cameroon, ${ }^{16}$ Eastern Nepal and Kerala. ${ }^{19,24}$ This may be associated with oxygen and nutrients supplied through the placenta 
Table 3 Bivariable and Multivariable Logistic Regression Analyses of Low Birth Weight in Public Hospitals Addis Ababa, 2019

\begin{tabular}{|c|c|c|c|c|c|c|c|}
\hline \multirow[t]{2}{*}{ Variable } & & \multicolumn{2}{|c|}{ LBW } & \multicolumn{2}{|c|}{ NBW } & \multirow[t]{2}{*}{ COR } & \multirow[t]{2}{*}{ AOR } \\
\hline & & $\mathbf{N}$ & $\%$ & $\mathbf{N}$ & $\%$ & & \\
\hline Maternal education & $\begin{array}{l}\text { Illiterate } \\
\text { Primary } \\
\text { Secondary } \\
\text { Higher }\end{array}$ & $\begin{array}{l}13 \\
33 \\
33 \\
11\end{array}$ & $\begin{array}{l}14.4 \\
36.7 \\
36.7 \\
12.2\end{array}$ & $\begin{array}{l}16 \\
68 \\
49 \\
47\end{array}$ & \begin{tabular}{l|l}
8.9 & \\
37.8 & \\
27.2 & \\
26.1 &
\end{tabular} & $\begin{array}{l}3.5(I .3-9.3) \\
2.07(0.95-4.5) \\
2.9(1.3-6.34) \\
I\end{array}$ & $\begin{array}{l}2.3(0.5-10) \\
2.2(0.74-6) \\
3.7(1.3-10.9)^{*}\end{array}$ \\
\hline Parity & $\begin{array}{l}\text { Primipara } \\
\text { Multipara }\end{array}$ & $\begin{array}{l}56 \\
34\end{array}$ & $\begin{array}{l}62.2 \\
37.8\end{array}$ & $\begin{array}{l}83 \\
97\end{array}$ & $\begin{array}{l}46.1 \\
53.9\end{array}$ & $\begin{array}{l}1.93(1.2-3.2) \\
1\end{array}$ & I.4(0.4-4.3) \\
\hline Pregnancy related complication & $\begin{array}{l}\text { Yes } \\
\text { No }\end{array}$ & $\begin{array}{l}34 \\
56\end{array}$ & $\begin{array}{l}37.8 \\
62.2\end{array}$ & $\begin{array}{l}26 \\
154\end{array}$ & $\begin{array}{l}14.4 \\
85.6\end{array}$ & $\begin{array}{l}3.6(1.98-6.5) \\
1\end{array}$ & $3(1.4-6.8)^{* *}$ \\
\hline Gestational HTN & $\begin{array}{l}\text { Yes } \\
\text { No }\end{array}$ & $\begin{array}{l}28 \\
62\end{array}$ & $\begin{array}{l}31.1 \\
68.9\end{array}$ & $\begin{array}{l}28 \\
152\end{array}$ & $\begin{array}{l}15.6 \\
84.4\end{array}$ & $\begin{array}{l}2.4(1.34-4.5) \\
\text { I }\end{array}$ & $3.7(1.6-8.6)^{* *}$ \\
\hline Nutritional counselling & $\begin{array}{l}\text { Yes } \\
\text { No }\end{array}$ & $\begin{array}{l}44 \\
46\end{array}$ & $\begin{array}{l}48.9 \\
51.1\end{array}$ & $\begin{array}{l}123 \\
57\end{array}$ & $\begin{array}{l}68.3 \\
31.7\end{array}$ & $\begin{array}{l}1 \\
2.3(1.34-3.8)\end{array}$ & \\
\hline Maternal height & $\begin{array}{l}\leq 155 \mathrm{~cm} \\
>155 \mathrm{~cm}\end{array}$ & $\begin{array}{l}11 \\
79\end{array}$ & $\begin{array}{l}12.2 \\
87.8\end{array}$ & $\begin{array}{l}7 \\
173\end{array}$ & 96.1 & $\begin{array}{l}3.4(1.3-9.2) \\
1\end{array}$ & $5.7(1.6-19)^{* *}$ \\
\hline Age of the mother & $\begin{array}{l}<20 \\
20-34 \\
\geq 35\end{array}$ & $\begin{array}{l}20 \\
61 \\
9\end{array}$ & $\begin{array}{l}22.2 \\
67.8\end{array}$ & $\begin{array}{l}13 \\
157 \\
10\end{array}$ & $\begin{array}{l}7.2 \\
87.2\end{array}$ & $\begin{array}{l}\text { I.7(0.5-5.34) } \\
0.43(0.2-I .1) \\
\text { I }\end{array}$ & $\begin{array}{l}0.5(0.9-2.6) \\
0.5(0.15-1.7)\end{array}$ \\
\hline Iron during Px & $\begin{array}{l}\text { Yes } \\
\text { No }\end{array}$ & $\begin{array}{l}65 \\
25\end{array}$ & $\begin{array}{l}72.2 \\
27.8\end{array}$ & $\begin{array}{l}145 \\
35\end{array}$ & $\begin{array}{l}80.6 \\
19.4\end{array}$ & $\begin{array}{l}\text { I } \\
\text { I.59(0.9-2.87) }\end{array}$ & $0.6(0.3-1.5)$ \\
\hline Anaemia & $\begin{array}{l}\text { Yes } \\
\text { No }\end{array}$ & $\begin{array}{l}14 \\
76\end{array}$ & $\begin{array}{l}15.6 \\
84.4\end{array}$ & $\begin{array}{l}17 \\
163\end{array}$ & $\begin{array}{l}9.4 \\
90.6\end{array}$ & $\begin{array}{l}\text { I.76(0.83-3.8) } \\
\text { I }\end{array}$ & $1.8(0.65-5.1)$ \\
\hline BMI & $\begin{array}{l}<18,5 \mathrm{~kg} / \mathrm{m}^{2} \\
18.5-24.9 \mathrm{~kg} / \mathrm{m}^{2} \\
\geq 25 \mathrm{~kg} / \mathrm{m}^{2}\end{array}$ & $\begin{array}{l}20 \\
54 \\
16\end{array}$ & $\begin{array}{l}22.2 \\
60.0 \\
17.8\end{array}$ & $\begin{array}{l}23 \\
126 \\
31\end{array}$ & $\begin{array}{l}12.8 \\
70.0 \\
17.2\end{array}$ & $\begin{array}{l}1.7(0.72-3.9) \\
0.83(0.42-1.64) \\
\text { I }\end{array}$ & $\begin{array}{l}0.9(0.2-3.8) \\
0.4(0.2-1.25)\end{array}$ \\
\hline Additional meals & $\begin{array}{l}\text { Yes } \\
\text { No }\end{array}$ & $\begin{array}{l}32 \\
58\end{array}$ & $\begin{array}{l}35.6 \\
64.4\end{array}$ & $\begin{array}{l}103 \\
77\end{array}$ & $\begin{array}{l}57.2 \\
42.8\end{array}$ & $\begin{array}{l}\text { I } \\
2.4(1.4-4.0)\end{array}$ & $2.2(0.85-5.77)$ \\
\hline ANC visit & $\begin{array}{l}\text { I-3 ANC } \\
\geq 4 \text { ANC }\end{array}$ & $\begin{array}{l}55 \\
25\end{array}$ & $\begin{array}{l}68.8 \\
31.3\end{array}$ & $\begin{array}{l}53 \\
121\end{array}$ & $\begin{array}{l}30.5 \\
69.5\end{array}$ & $\begin{array}{l}8(2.7-24.2) \\
1\end{array}$ & $6.9(3-15)^{* * *}$ \\
\hline Maternal MUAC & $\begin{array}{l}<23 \mathrm{~cm} \\
\geq 23 \mathrm{~cm}\end{array}$ & $\begin{array}{l}35 \\
55\end{array}$ & $\begin{array}{l}38.9 \\
61.1\end{array}$ & $\begin{array}{l}43 \\
137\end{array}$ & $\begin{array}{l}23.9 \\
76.1\end{array}$ & $\begin{array}{l}2.03(1.2-3.5) \\
1\end{array}$ & $1.4(0.6-2.9)$ \\
\hline Pre-pregnancy weight & $\begin{array}{l}<50 \mathrm{~kg} \\
\geq 50 \mathrm{~kg}\end{array}$ & $\begin{array}{l}54 \\
36\end{array}$ & $\begin{array}{l}60.0 \\
40.0\end{array}$ & $\begin{array}{l}90 \\
90\end{array}$ & $\begin{array}{l}50.0 \\
50.0\end{array}$ & $\begin{array}{l}1.5(0.9-2.5) \\
1\end{array}$ & $1.6(0.7-3.9)$ \\
\hline Gravidity & $\begin{array}{l}\text { Primigravida } \\
\text { Multigravida }\end{array}$ & $\begin{array}{l}47 \\
43\end{array}$ & $\begin{array}{l}52.2 \\
47.8\end{array}$ & $\begin{array}{l}65 \\
115\end{array}$ & $\begin{array}{l}36.1 \\
63.9\end{array}$ & $1.9(1.2-3.2)$ & $1.37(0.4-4.3)$ \\
\hline
\end{tabular}

Notes: *Statistically significant with $P$ value $\leq 0.05$. **Statistically significant with $P$ value $\leq 0.01$. ***Statistically significant with $P$ value $\leq 0.001$

Abbreviations: ANC, Antenatal care; BMI, Body mass index; HTN, Hypertension; MUAC, Mid-upper arm circumference; PX, pregnancy; Kg, kilogram; Cm, centimetre.

to the foetus becomes compromised as a result of vasoconstriction of blood vessel walls during hypertensive state result in $\mathrm{LBW}^{23}$

Moreover, this study revealed that mothers who faced pregnancy-related complications were three times riskier delivering babies of low birth weight than mothers who did not have complications with [AOR 3.08 (95\% CI 1.4-6.8)]. The result of this study is similar to studies conducted in referral hospitals in Northern Ethiopia. ${ }^{25}$ Similarly, case-control study in the Amhara region revealed a similar finding. ${ }^{21}$ This is because of most women with such pregnancy-related complication (blurred 
vision, severe headache, epigastric pain, vaginal bleeding, fever, severe abdominal pain) which results in decreasing nutrition and oxygen perfusion to the foetus which leads to low-birth-weight or death. ${ }^{21}$

The results of this study also revealed that the birth weight of a neonate is predicted by maternal educational status. Mothers who attended secondary education were four times more likely to give low birth weight than mothers who attended higher education [AOR (95\% CI) $3.76(1.3-10.9)]$. This result is also similar to a study conducted in Wolaita Sodo and Bale zone. ${ }^{26,27}$ The observed association possibly might be due to inadequate diet as a result of low dietary literacy. Furthermore, the low educational status may also lead to limited access to prenatal care, mainly in places where mothers are expected to pay for service. Lower education limits women from having independent decisions and good access to family resources which are very important for better nutrition. ${ }^{14,28}$

Furthermore, in this study, we also found that nutrition counselling during pregnancy had no significant association with giving low birth weight (AOR 0.508(0.188-1.369) $\mathrm{P}$ 0.18). This result is contrary to a case-control study in North Shoa Central Ethiopia that revealed mothers with no history of nutrition counselling during pregnancy had three times increased odds of giving LBW babies than those who were counseled. ${ }^{7}$ The nutritional status of the new-borns ultimately depends on the nutritional status of the mothers during the time of pregnancy because the baby solely depends on placental feeding throughout the entire pregnancy. This may be due to high maternal health utilization, easy accessibility, and availability of health institution getting pregnant mother nutritional counselling.

\section{Limitation}

This study was Institutional based, and therefore it may not be as good as population-based studies to generalize the results in the population.

\section{Conclusion}

Low birth weight is a significant public health concern that is linked to multiple factors. According to the findings of this study, the independent predictors of LBW were maternal height $\leq 155 \mathrm{~cm}$, complications during pregnancy, gestational hypertension, incomplete ANC follow-up, and low maternal education level.

\section{Abbreviations}

ANC, Antenatal Care; AOR, Adjusted Odds Ratio; APH, Antepartum Haemorrhage; BW, Birth Weight; CS, Caesarean Section; EDHS, Ethiopia Demographic and Health Survey; GA, Gestational Age; HTN, Hypertension; IUGR, Intrauterine Growth Retardation; LBW, Low Birth Weight; MUAC, Mid Upper Arm Circumference; NBW, Normal Birth Weight; PIH, Pregnancy-Induced Hypertension; SGA, Small-for-Gestational Age; VLBW, Very Low Birth Weight.

\section{Data Sharing Statement}

Data support these findings are contained within the manuscript and will share upon request to the corresponding author.

\section{Ethics and Consent Statement}

The study was approved by the Institutional Review Board (IRB) College of Medicine and Health Sciences, Addis Ababa University with IRB Protocol number 035/19/SNM. A permission letter was taken from the Addis Ababa health bureau and submitted to hospitals. A written consent was obtained from all caregivers, and this study is done in accordance with the Declaration of Helsinki.

\section{Consent}

The authors confirm that all caregivers provided informed consent forms.

\section{Acknowledgment}

First, we would like to express our deepest gratitude and appreciation to Addis Ababa University, College of Health Sciences for providing financial support to complete this research project. We would like to sincerely acknowledge Mr. Birhanu Ayelign for editorial assistance. We would also like to extend our appreciation to the data collectors and participants in the study.

\section{Author Contributions}

All authors contributed to data analysis, drafting or revising the article, gave final approval of the version to be published and agreed to be accountable for all aspects of the work.

\section{Funding}

The study was funded by Addis Ababa University, Ethiopia. The funder had no role in the study design, data collection, and analysis, interpretation of data, the decision to publish, or preparation of the manuscript. 


\section{Disclosure}

The authors declare that they have no competing interests.

\section{References}

1. Sebayang SK, Dibley MJ, Kelly PJ, Shankar AV, Shankar AH, Group SS. Determinants of low birthweight, small-for-gestationalage and preterm birth in Lombok, Indonesia: analyses of the birthweight cohort of the SUMMIT trial. Trop Med Int Health. 2012;17 (8):938-950

2. Deshpande Jayant D, Phalke D, Bangal V, Peeyuusha D. Maternal risk factors for low birth weight neonates: a hospital-based case-control study in rural areas of western maharashtra, India. Natl J Community Med. 2011;2(3):394-398.

3. Atitwa EB. Socio-economic determinants of low birth weight in Kenya: an application of logistic regression model. Am J Theor Appl Stat. 2015;4(6):438-445. doi:10.11648/j.ajtas.20150406.14

4. Wardlaw TM. Low Birthweight: Country, Regional and Global Estimates. Unicef; 2004.

5. Zenebe K, Awoke T, Birhan N. Low Birth Weight \& Associated Factors Among Newborns in Gondar Town, North West Ethiopia: Institutional Based Cross-Sectional Study. 2014.

6. Mengesha HG, Wuneh AD, Weldearegawi B, Selvakumar DL. Low birth weight and macrosomia in Tigray, Northern Ethiopia: who are the mothers at risk? BMC Pediatr. 2017;17(1):144. doi:10.1186/ s12887-017-0901-1

7. Sutan R, Mohtar M, Mahat AN, Tamil AM. Determinant of low birth weight infants: a matched case-control study. Open J Prev Med. 2014;4(03):91. doi:10.4236/ojpm.2014.43013

8. UNICEF. The State of the World's Children 2008: Child Survival. Unicef; 2007.

9. UNICEF D. Monitoring the Situation of Children and Women; 2005.

10. Lawn JE, Gravett MG, Nunes TM, Rubens CE, Stanton C. Global report on preterm birth and stillbirth (1 of 7): definitions, description of the burden and opportunities to improve data. BMC Pregnancy Childbirth. 2010;10(1):S1. doi:10.1186/1471-2393-10-S1-S1

11. Statistics. UE. Low Birthweight-Country-Regional-And-GlobalEstimates; 2017

12. Health. TFDRoEMo. National Newborn and Child Survival Strategy Document Summary 2015/16-2019/20. FMOH/MCH, Editor. Directorate. Addis Ababa; 2015.

13. Fulton C. Improving neonatal mortality in an Ethiopian referral hospital. BMJ Open Qual. 2013;2(2):u202086. w1064.

14. Gizaw B, Gebremedhin S. Factors associated with low birthweight in North Shewa zone, Central Ethiopia: a case-control study. Ital J Pediatr. 2018;44(1):76. doi:10.1186/s13052-018-0516-7

15. EDHS E. Demographic and Health Survey 2016: Key Indicators Report. The DHS Program ICF; 2016.
16. Njim T, Atashili J, Mbu R, Choukem S-P. Low birth weight in a sub-urban area of Cameroon: an analysis of the clinical cut-off, incidence, determinants, and complications. BMC Pregnancy Childbirth. 2015;15:288. doi:10.1186/s12884-015-0723-9

17. Noureddine E, Abdellatif B. Prevalence and determinants of low birth weight: a case-control study in Marrakesh (morocco). Iran J Public Health. 2015;44(3):422.

18. Mumbare SS, Maindarkar G, Darade R, Yenge S, Tolani MK, Patole K. Maternal risk factors associated with term low birth weight neonates: a matched-pair case-control study. Indian Pediatr. 2012;49 (1):25-28. doi:10.1007/s13312-012-0010-z

19. Bhaskar RK, Deo KK, Neupane U, et al. A case-control study on risk factors associated with low birth weight babies in Eastern Nepal. Int J Pediatr. 2015;2015:807373. doi:10.1155/2015/807373

20. Inoue $\mathrm{S}$, Naruse $\mathrm{H}$, Yorifuji $\mathrm{T}$, Kato $\mathrm{T}$, Murakoshi $\mathrm{T}$, Doi $\mathrm{H}$. Association between short maternal height and low birth weight: a hospital-based study in Japan. J Korean Med Sci. 2016;31 (3):353-359. doi:10.3346/jkms.2016.31.3.353

21. Asmare G, Berhan N, Berhanu M, Alebel A. Determinants of low birth weight among neonates born in Amhara Regional State Referral Hospitals of Ethiopia: an unmatched case-control study. BMC Res Notes. 2018;11:447. doi:10.1186/s13104-018-3568-2

22. Assefa N, Berhane Y, Worku A. Wealth status, mid-upper arm circumference (MUAC) and antenatal care (ANC) are determinants for low birth weight in Kersa, Ethiopia. PLoS One. 2012;7(6):e39957. doi:10.1371/journal.pone.0039957

23. Gebrehawerya T, Gebreslasie K, Admasu E, Gebremedhin M. Determinants of low birth weight among mothers who gave birth in Debre Markos Referral Hospital, Debremarkos Town, East Gojam, Amhara Region, Ethiopia. J Neonatal Pediatr Med. 2018;04(01). doi:10.4172/2572-4983.1000145

24. Ismail IM, Venugopalan P. Case-control study on risk factors of low birth weight in a tertiary care hospital, Kerala. Ann Community Health. 2016;4(3):5-12.

25. Hailu LD, Kebede DL. Determinants of low birth weight among deliveries at a referral hospital in Northern Ethiopia. Biomed Res Int. 2018;2018:8169615. doi:10.1155/2018/8169615

26. Kastro S, Demissie T, Yohannes B. Low birth weight among term newborns in Wolaita Sodo town, South Ethiopia: a facility-based cross-sectional study. BMC Pregnancy Childbirth. 2018;18:160. doi:10.1186/s12884-018-1789-y

27. Demelash H, Motbainor A, Nigatu D, Gashaw K, Melese A. Risk factors for low birth weight in Bale zone hospitals, South-East Ethiopia: a case-control study. BMC Pregnancy Childbirth. 2015;15 (1):264. doi:10.1186/s12884-015-0677-y

28. Ngwira A, Stanley CC. Determinants of low birth weight in Malawi: bayesian geo-additive modeling. PLoS One. 2015;10(6):e0130057. doi:10.1371/journal.pone. 0130057
Pediatric Health, Medicine and Therapeutics

\section{Publish your work in this journal}

Pediatric Health, Medicine and Therapeutics is an international, peerreviewed, open access journal publishing original research, reports, editorials, reviews and commentaries. All aspects of health maintenance, preventative measures and disease treatment interventions are addressed within the journal. Practitioners from all disciplines are invited to submit their work as well as healthcare researchers and patient support groups. The manuscript management system is completely online and includes a very quick and fair peer-review system. Visit http://www.dovepress.com/testimonials.php to read real quotes from published authors. 